\title{
Mario Henrique Simonsen
}

\author{
RUBENS PENHA CYSNE
}

$\mathrm{D}$ IFERENTES AUTORes têm escrito sobre as contribuições de Mario Henrique Simonsen à teoria econômica, ao pensamento econômico nacional, à econômica brasileira, bem como ao delineamento de algumas de nossas instituições (a CVM em particular). Tal literatura, à qual o professor Ney Coe de Oliveira, ex-diretor administrativo da EPGE, refere-se (Oliveira, 2000) como Coletânea Simonsen, tem sido paulatinamente formada mediante colaborações avulsas de seus ex-alunos e parceiros de trabalho.

Neste artigo, estaremos interessados apenas nas adições de cunho acadêmico. Um sucinto relato de outras áreas em que Simonsen atuou, bem como considerações de ordem mais pessoal (e.g., Leal, 1998; Campos, 1998), podem ser encontradas na Edição Especial da RBE - Revista Brasileira de Economia, organizada por Faro (1998), publicada em homenagem ao Professor (1). Nessa edição da RBE há também dois artigos (Lemos \& Schymura, 1998; Cysne, 1998) que tecem considerações sobre a atuação de Simonsen na questão da política antitruste no Brasil (2). Cabe notar também, na mesma edição, o artigo de Werlang (1998), ao qual voltaremos a nos referir no que segue.

Além dos artigos já reunidos na referida edição especial da RBE, podem-se mencionar algumas outras obras - seja em andamento ou já publicadas - que perfazem a Coletânea Simonsen. Incluem-se nesse conjunto uma pesquisa conduzida pelo Núcleo de História Oral da FGV, outra pela Sul América, bem como importantes artigos de cunho mais acadêmico, como os de Barbosa (1997) e Boianovsky (1999). Suplementarmente, numa ligeira revisão histórica, Cysne (2001) compara as projeções de Kahn \& Wiener (1967), publicadas pelo Instituto Hudson, relativas ao ano 2000, com os fatos efetivamente ocorridos. Tais previsões foram uti-lizadas por Simonsen em dois de seus mais famosos livros: Brasil 2001 (1969) e Brasil 2002 (1972).

Roberto de Oliveira Campos (1998) enumera cinco contribuições teóricas de Simonsen:

- a chamada "curva de Simonsen", que descreve a evolução do salário real ao longo do tempo, quando a inflação é positiva e a correção salarial se dá em períodos discretos no tempo;

- a teoria dos três determinantes da inflação, englobando a componente autônoma, a de realimentação e a de regulagem de demanda; 
- a política de rendas, como instrumento adicional a ser utilizado quando se pretende debelar um processo inflacionário existente sob um regime de indexação;

- a regra de endividamento prudencial;

- a crítica da hipótese de convergência imediata a um equilíbrio de Nash, assumida pela Escola de Expectativas Racionais.

Werlang (1998), em artigo já mencionado, salienta que “a contribuição teórica mais importante de Mario Henrique Simonsen foi o aumento da compreensão dos fenômenos inflacionários e a crítica à teoria das expectativas racionais". Por outro lado, Barbosa (1997) lista como contribuições mais importantes do Professor a "curva de Simonsen", o modelo de realimentação da inflação e a justificativa teórica do uso da política de rendas como um dos instrumentos de combate à inflação.

Tanto os pontos levantados por Werlang (1998), quanto por Barbosa (1997), enquadram-se na taxonomia efetuada por Campos (1998), mais precisamente, nos quatro primeiros itens - a "curva de Simonsen", a teoria dos três determinantes da inflação, a política de rendas e a crítica da hipótese de convergência imediata a um equilíbrio de Nash em expectativas racionais. Observe-se, entretanto, que Werlang (1998) e Barbosa (1997) apresentam um efetivo detalhamento técnico e das referências bibliográficas de cada um dos pontos levantados, constituindo-se desta forma em leitura obrigatória para aqueles que desejam se aprofundar em tais questões. Por sua vez, Boianovsky (1999) chama a atenção para uma contribuição adicional de Simonsen, relacionada à literatura que tenta modelar a demanda por moeda da parte dos agentes econômicos com base em uma restrição cash-in-advance. Segundo Boianovsky, o trabalho de Simonsen (1964) destaca-se, historicamente, pela introdução da restrição cash-in-advance, sob a forma de desigualdade, em um problema de programação não-linear.

\section{Quatro contribuições adicionais}

Nosso objetivo principal no presente texto é destacar um conjunto de quatro campos adicionais nos quais Mario Henrique Simonsen contribuiu (3) para o desenvolvimento do conhecimento acadêmico então existente. Tais campos não são mencionados em qualquer dos artigos já mencionados. Deter-me-ei mais especificamente no detalhamento dos dois últimos, (Contabilidade com juros reais e Custos de bem-estar da inflação), em função de minha maior familiaridade com esses temas.

\section{Condição de transversalidade na otimização dinâmica}

O primeiro ponto foi-me lembrado por Aloisio Araujo (2000), que trabalhou com Simonsen por vários anos como colega da EPGE-FGV. Após a sua saída 
do Ministério do Planejamento, em agosto de 1979, Simonsen dedicou-se a escrever aquele que seria seu livro-texto de maior influência na formação macroeconômica de toda uma geração de economistas formados pela EPGE-FGV (em particular, o autor deste artigo, Sergio Ribeiro da C. Werlang e Carlos Ivan Simonsen Leal, os três da mesma turma da EPGE-FGV, de 1981).

Trata-se de Dinâmica macroeconômica, texto que por si só poderia originar um artigo à parte na Coletânea Simonsen. Araujo lembrou-me, ao saber-me escriba do presente texto, da dedução original da condição de transversalidade, em problemas de otimização dinâmica, efetuada por Simonsen no capítulo VI desse livro.

\section{Vulnerabilidade a choques com moeda indexada}

Um segundo ponto diz respeito à formalização, efetuada por Simonsen (1991), e posteriormente por Pastore (1996), este em um contexto keynesiano estático, da maior vulnerabilidade a choques em uma economia na qual a dívida pública - tal como ocorreu no Brasil no caso das LBCs (Letras do Banco Central) e LFTs (Letras do Tesouro) - se atrela ao juro de curto prazo. Trata-se, esse trabalho de Simonsen, de uma formalização que serviu de balizamento a uma antiga discussão sobre política monetária, específica ao caso brasileiro, à qual o meio profissional costumava se referir como o problema da zeragem, ou da moeda indexada. Segundo Simonsen (1991), esse tipo de vulnerabilidade explica a escalada da inflação ao final do governo Sarney.

\section{Contabilidade com juros reais}

Embora Simonsen tenha trabalhado ativamente, desde 1964, em diferentes aspectos relacionados à questão da indexação e da contabilidade inflacionária (veja, por exemplo, Simonsen, 1995; Chacel et al., 1970), deter-nos-emos aqui apenas na questão da distinção, do ponto de vista contábil, entre juros nominais e juros reais.

Tal distinção aplica-se para qualquer agente econômico. Para as empresas, é importante tanto na questão fiscal, quando se evita a taxação dos chamados lucros ilusórios, quanto na questão societária, quando se evita a distribuição indevida dos mesmos. Para o governo, é importante no cálculo da renda líquida, da poupança e do déficit. E, para as Contas Nacionais, no cálculo da distribuição da renda entre famílias, empresas, setor público e setor externo.

A fim de elucidar esse ponto, seguiremos uma estratégia baseada em três etapas. Inicialmente, mostramos que discussão sobre a distinção entre juros nominais e juros reais, do ponto de vista contábil, tem preocupado os economistas pelo menos desde o início do século XX. Em seguida, apresentamos algumas motivações de ordem aplicada para o estudo da questão. Por último, fazemos ligeira digressão sobre a literatura relativa ao tema, contrapondo-a cronológica e metodologicamente às possíveis contribuições de Simonsen nessa área. 
ASPECTOS HISTÓRICOS - A CONTABILIZAÇÃO com juros reais nada mais faz do que obedecer à noção de renda estipulada nas pioneiras contribuições de Haig (1921) e Hicks (1939). Tais autores definem renda tomando como base o consumo que mantém o poder aquisitivo de ativos ou passivos líquidos.

Haig (1921, p. 27) destaca: "income is the money-value of the net accreation to economic power between two points of time" ou ainda (p. 21): "the economist, when asked whether a particular item is in-come or is not income, must, in the opinion of the writer, make his reply depend upon whether the receipt of that item has increased the economic power of the recipient to command satisfaction yielding goods or services".

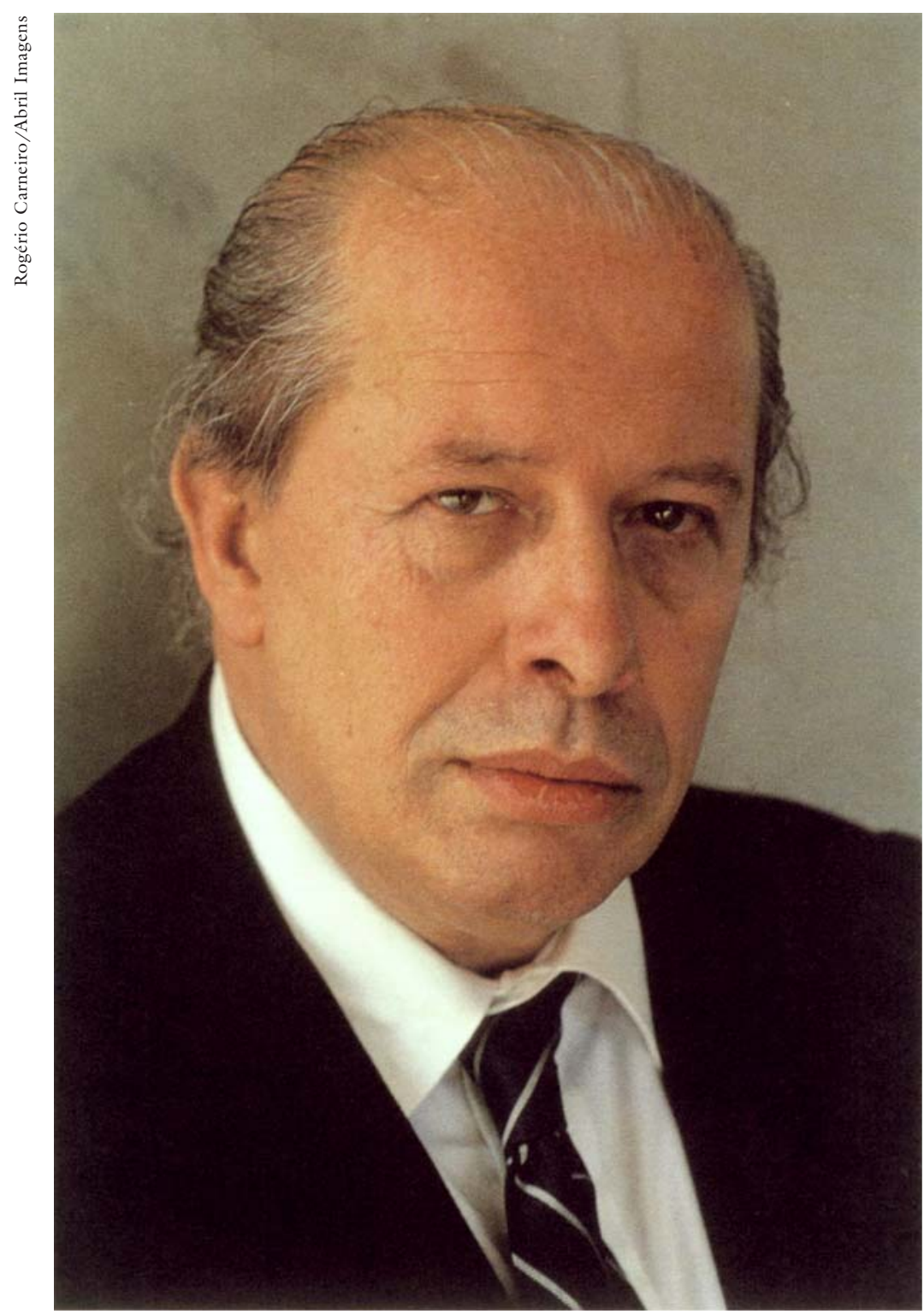

Mario Henrique

Simonsen (1935-1996) 
Lê-se da mesma forma, em Hicks, no capítulo 14 de Value and Capital, que se dedica à definição de renda (p. 172): "the purpose of income calculations in practical affairs is to give people an indication of the amount which they can consume without impovering themselves".

Como se obseva, nem Haig nem Hicks contabilizariam, como renda dos indivíduos, das empresas, ou do governo, a parcela dos juros referente à simples reposição inflacionária do valor real de passivos ou ativos. Na ausência de ilusão monetária, tais montantes não deveriam modificar a definição apropriada de renda pessoal disponível, nem o nível de consumo agregado.

IMPORTANCIA DO TEMA - EMBORA uma questão, a princípio, de conotação puramente contábil, a utilização de juros nominais ou reais no cálculo de agregados macroeconômicos pode se mostrar de grande relevância prática. A título de ilustração, descrevemos, a seguir, um episódio ocorrido com o Brasil em meados de 1983 (4).

Ao final de 1982, o governo brasileiro concluíra uma Carta de Intenções com o FMI - efetivamente assinada ao início de 1983 -, pela qual esta agência liberaria créditos para o país, contanto que certas restrições macroeconômicas fossem atendidas. Tais restrições refletiam a idéia, do Fundo, de que o Brasil deveria fazer a sua parte no ajuste, reduzindo o total do dispêndio (consumo mais investimento, fosse privado ou do governo).

Uma das restrições acordadas na Carta estipulara o valor máximo do déficit público (no caso, Necessidades de Financiamento do Setor Público - NFsPs) a vigorar em 1983. Ocorre que as NFSPS faziam referência a juros nominais, e não a juros reais. Assim, quando a inflação brasileira se elevou de patamar, em parte devido à maxidesvalorização de 30\% em 18 de fevereiro de 1983, tendo passado da média anual em torno de $100 \%$ - vigente entre 1980 e 1982 - para algo em torno de $220 \%$ - média 1983-85 -, os juros nominais incidentes sobre a dívida pública também subiram, e com eles as NFSPS.

Como as metas para o déficit haviam sido fixadas com base em uma inflação anual em torno de $100 \%$, não houve como cumprir o acordado e o Brasil foi declarado como não tendo honrado as condições necessárias para a liberação de novos créditos em moeda forte. Isto posto, o freio ao qual a economia teve de ser submetida implicou o cancelamento de vários projetos de investimento, a redução de estoques e, como não poderia deixar de ser, nesta conjuntura desfavorável, a perda de vários empregos. Temos nesse episódio uma demonstração clara de como a falta de sistematização de uma simples questão contábil pode afetar significativamente a vida de várias famílias.

Posteriormente, a indesejável dependência dos objetivos macroeconômicos acordados em Cartas de Intenção com relação à taxa de inflação foi reconhecida 
pelo FMI, passando essas a serem assinadas, no ano de 1983, com referência ao déficit público exceto correção monetária da dívida.

Entretanto, havia ainda aqueles que, não-convencidos da propriedade da utilização do novo conceito, insistiam na manutenção da sistemática antiga, centrada na utilização de juros nominais. $\mathrm{O}$ arrazoado dessa oposição baseava-se em uma espécie de defesa de um estabilizador automático. Argumentava-se que, sempre que a inflação se elevasse acima do previsto, seria esse mais um motivo para que a redução do crédito interno líquido fosse ainda mais severa. Faltava a esses analistas a constatação de que não é necessariamente ótimo impor uma trajetória de amortização da dívida como função crescente da taxa de inflação (um governo que zere seu déficit nominal sujeito a uma inflação de $200 \%$ ao ano terá amortizado dois terços do poder aquisitivo de sua dívida ao final do ano, ou três quartos se a inflação tiver sido de $300 \%$, e assim por diante).

A distinção entre juros nominais e juros reais é também importante nas Contas Nacionais, particularmente no que diz respeito à repartição da renda entre os diferentes setores da economia (governo, famílias, empresas e setor externo). Para um analista que se detenha sobre os agregados macroeconômicos de um país com um setor público muito endividado (em termos líquidos) e com elevada inflação, os dados, calculados com juros nominais, da poupança bruta do setor privado e da poupança do governo, são de pouca utilidade. De fato, o elevado pagamento de juros pelo governo ao setor privado implica uma poupança bruta do setor privado artificialmente inflada, e uma poupança do governo artificialmente reduzida (no Brasil, em períodos de inflação elevada, ela chegou a vários pontos percentuais negativos do PIB). Artificialmente, devido ao fato de boa parte de tais juros (aqueles que se referem à inflação) nada mais fazer do que repor o valor real das obrigações do governo.

Este tipo de dificuldade com a interpretação de tais estatísticas das Contas Nacionais costuma ser em parte contornado mediante a utilização apenas da poupança interna, dada pela soma da poupança bruta do setor privado com a poupança do governo. Observe-se, entretanto, que tal tipo de contorno implica a extinção da possibilidade de se inferir sobre a repartição da renda entre setor privado e governo. Em adição, se o objetivo é o cálculo da poupança total, devese lembrar que a existência de inflação na moeda estrangeira de referência - usualmente o dólar - gera também a necessidade de correção da poupança externa pela diferença entre juros nominais e reais - em dólar (5).

Mas, não é apenas do ponto de vista de política econômica que a distinção entre agregados macroeconômicos (déficit público em particular) calculados com juros nominais e com juros reais é importante. Tome-se por exemplo a estimativa econométrica da função consumo. O consumo é função da renda pessoal disponível, que por sua vez é obtida da renda interna líquida subtraindo-se: a renda 
líquida enviada para o exterior; a renda líquida do setor público; os lucros retidos das empresas.

Para um país com inflação e dívida pública elevados, o item renda líquida enviada para o exterior pode diferir substancialmente na contabilidade com juros nominais e na contabilidade com juros reais, afetando os dados a serem utilizados na análise empírica. Se se supõe ausência de ilusão monetária, os detentores da dívida saberão que o valor dos juros correspondentes à inflação nada mais faz do que repor o seu valor real. Isto posto, o consumo será função da renda pessoal disponível calculada com juros reais, e não nominais.

Duas motivações adicionais para a distinção entre juros nominais e reais dão-se na questão fiscal e na questão societária. No primeiro caso, taxação sobre juros nominais na presença de inflação implica que parte dessa taxação seja na verdade tributação sobre o patrimônio, e não sobre a renda de juros. No segundo caso, distribuições de dividendos que não distingam entre juros nominais e reais podem estar, na verdade, descapitalizando empresas credoras líquidas.

A LITERATURA INTERNACIONAL SOBRE O ASSUNTO - A LITERATURA relativa à delimitação de normas e procedimentos contábeis distinguindo entre juros nominais e reais concentrou-se fundamentalmente entre o final da década de 70 e o final dos anos 80. Sua expansão ao final da década de 70 explica-se em função da elevação das taxas de inflação, em várias economias industrializadas, que se seguiu à primeira crise do petróleo, em 1973. Por outro lado, a literatura a partir de meados dos anos 80 foi mais motivada pela discussão sobre as Cartas de Compromisso que vários países firmaram com o FMI em seguida à crise de pagamentos internacionais deflagrada pela moratória do México, em 1982. Nessa segunda fase, o interesse maior foi com respeito à definição do déficit do setor público, não se atendo as publicações, especificamente, nem sobre as Contas Nacionais nem sobre as questões fiscais ou societárias envolvendo empresas.

Blejer \& Cheasty (1991), na seção 6 de seu trabalho, intitulada The operational deficit: removing the effects of inflation from interest payments, elaboram um pequeno survey sobre a questão da contabilidade com juros reais, no que diz respeito às contas públicas. O texto pode servir de ponto de partida para uma pesquisa histórica na área, principalmente no que diz respeito à literatura da década de 80 .

Não há citação de trabalhos que tenham sido publicados na década de 70. Também não há, em Blejer \& Cheasty, referências a trabalhos que estendam a metodologia de contabilidade com juros reais para as Contas Nacionais e empresas, de forma integrada.

Entre os trabalhos mencionados pelos autores, Eisner (1984) dedicou-se a discutir questões de política econômica levando em consideração os números 
corrigidos do déficit norte-americano. A fórmula do déficit calculado com juros reais é apresentada por ele de forma bastante simplificada (por exemplo, não distingue entre dívida denominada em moeda doméstica e aquela denominada em moeda estrangeira). Sua parte metodológica remete o leitor a Eisner \& Pieper (1984). Do ponto de vista teórico, a importância desse último paper foi reconhecer que a medida do déficit público calculada com juros nominais pode ser pouco adequada em períodos de alta inflação. Os trabalhos de Haig e Hicks detalhados na seção anterior são apresentados como suporte à idéia de que a medida correta do déficit público deveria ser aquela que iguala esse fluxo à variação do valor real do passivo líquido do agente econômico em questão.

Gil-Diaz (1986) desenvolveu uma seção teórica (em tempo discreto) sobre o assunto, levando em consideração também o impacto de variações da taxa real de câmbio sobre o poder aquisitivo de dívidas denominadas em diferentes moedas. Tais desenvolvimentos foram posteriormente aplicados por Gil-Diaz em análise das estatísticas fiscais mexicanas entre 1970 e 1983.

Outro autor, Catsambas (1988), apresentou um tratamento teórico bastante claro do assunto, assumindo também uma postura mais crítica no que diz respeito à hipótese de ausência de ilusão monetária sobre a qual se assenta a defesa da utilização de estatísticas fiscais corrigidas. Tanto Catsambas (1988) quanto Gil-Diaz (1986) fazem menção ao trabalho de Taylor \& Threadgold (1979) como um dos primeiros a sugerir ajustes para as contas públicas em função da inflação.

Em termos de referências Taylor \& Threadgold estão para a literatura da década de 70 como Blejer e Cheasty estão para a literatura da decada de 80: tratase de excelente ponto de partida para uma pesquisa dos trabalhos na área. Eles são também excelente fonte de referência sobre o estágio dos procedimentos contábeis distingüindo entre juros nominais e reais, ao final da década de 70. Em primeiro lugar, fica claro que a questão de forma alguma restingia-se apenas à contabilidade pública. A idéia estendia-se também a empresas e às Contas Nacionais.

Do ponto de vista histórico, observe-se que, em 1978, Kennedy (1978) publicou uma crítica aos trabalhos do Sandilands Committee (Inflation Accounting Committee), publicados em 1975 e, até então, a norma sugerida para ajustes inflacionários de balanços: "they fail to allow for the gains that accrue to the equity interest in companies through the effect of inflation in eroding the value of monetary liabilities."

A EVOLUÇÃO DA QUESTÃO NO BRASIL - NO INÍCIO dos anos 80 gerou-se, no Brasil, certa confusão conceitual sobre a distinção, na questão relacionada ao cálculo do déficit público, entre a utilização de juros nominais e de juros reais. Primeiro porque, numa tentativa de brevidade semântica, houve referências (6), 
que se mostraram posteriormente inadequadas, do ponto de vista didático, ao agregado macroeconômico (déficit, poupança, renda líquida etc.) calculado com juros nominais (ACJN), como agregado nominal, e ao agregado calculado com juros reais (ACJR), como agregado real. Isto posto, alguns pensaram tratar-se de uma questão de deflacionamento de séries históricas, quando esse não era o caso. De fato, a passagem de um a outro conceito - ACJN a ACJR - dá-se com respeito a um fluxo calculado durante um determinado período contábil, e não com o objetivo de delimitar o poder aquisitivo de certa grandeza monetária avaliada em um ponto fixo no tempo (a relação entre tais conceitos se dá através do princípio Haig-Hicks, pelo qual ao déficit calculado com juros reais deve se contrapor idêntica variação do poder aquisitivo - ou seja, do valor deflacionado - dos passivos líquidos do agente econômico em questão).

Segundo, porque a passagem da contabilidade com juros nominais à contabilidade com juros reais permite certo grau de liberdade no que diz respeito ao imposto inflacionário. Quando a contabilidade é feita do início ao fim com juros reais, incluindo aí os ativos líquidos das Autoridades Monetárias (que se consolidam ao governo), chega-se ao conceito de DCJR, o único que satisfaz ao critério de Haig-Hicks anteriormente citado. Por outro lado, quando se exclui a base monetária desse princípio, chega-se ao conceito de déficit operacional.

Em outras palavras, o déficit operacional difere do DCJR por não levar a crédito do setor público o juro real negativo pago pela base monetária (veja, por exemplo, Simonsen \& Cysne (1985; 1987; 1989, capítulo 3; 1995, capítulo 3). Ou seja, o déficit operacional é igual ao DCJR mais o imposto inflacionário. A utilidade do conceito operacional é impedir que o imposto inflacionário, sendo lançado a crédito do governo na contabilidade com juros reais, mascare possíveis desequilíbrios das contas públicas.

As definições teóricas apresentadas em Simonsen \& Cysne (1985; 1987; 1989; 1995 ) partem da premissa de ausência de ilusão monetária da parte dos agentes econômicos e orientam-se sobre o seguinte tripé: toda contabilidade - seja com juros reais ou nominais - deve ser feita sempre sob o critério contábil de competência, e não de caixa; deve ser definido setor público sob o parâmetro macro-econômico de controlabilidade; a passagem da contabilidade com juros nominais a juros reais deve ser efetuada com o índice inflacionário que mais se aproxime daquele relevante para o consumidor representativo.

As CONTRIbuiÇões de Simonsen - AS PUblicaÇÕes de ordem mais didática de Simonsen sobre a contabilidade com juros reais e nominais, como se observa dos trabalhos até aqui mencionados, iniciaram-se fundamentalmente em 1985, portanto pelo menos sete anos após as primeiras críticas (e.g., Kennedy, 1978) à contabilidade que não distinguia entre juros nominais e reais. Entretanto, nossa 
conjectura, sobre a qual sugerimos pesquisa adicional posterior por profissionais da área de História do Pensamento Econômico, é de que o aparato direta ou indiretamente criado por Simonsen, no que diz respeito à contabilização com juros reais na economia brasileira, tenha se antecipado à literatura internacional sobre o assunto. De fato, há registros claros, na legislação nacional de correção monetária, sobre a qual Simonsen teve reconhecida influência, da utilização de sofisticados mecanismos contábeis distinguindo entre juros nominais e juros reais.

Já ao final do governo Castello Branco foi editado um texto, o Decreto-Lei n. ${ }^{\circ} 62$, que estipulava métodos bastante sofisticados de correção monetária de balanços. Esse texto, que não chegou a ser implementado, "refinava a idéia de manutenção do capital de giro, calculando-a por um método preciso, e tornando-a automaticamente dedutível do lucro sujeito a imposto e incorporável ao capital” (Simonsen, 1970: 188) (7).

Exemplo mais recente nesse sentido, do final da década de 70, é dado pelo Decreto n. ${ }^{\circ} 1578$, que visava a filtrar os efeitos da inflação sobre as demonstrações de lucros e perdas, tanto para efeitos societários quanto para o cálculo do imposto de renda das pessoa jurídicas. Ocorre que tal metodologia, como mostrado em Simonsen \& Cysne (1995: capítulo 3) é equivalente àquela que define a passagem do déficit público calculado com juros nominais ao déficit público calculado com juros reais. Também nesse texto é demonstrado que o lucro corrigido pelas técnicas de ajuste inflacionário de balanços é igual ao lucro real das Contas Nacionais corrigido pelas perdas ou ganhos de capital decorrentes de desvalorizações da taxa real de câmbio (a distinção reflete um princípio básico das Contas Nacionais de não-inclusão de ganhos ou perdas de capital).

Nas contribuições de Simonsen anteriormente citadas, cabe salientar ainda as fórmulas de conversão da contabilidade nominal em contabilidade real em tempo contínuo, quando se assume que a posse de ativos monetários líquidos da parte de qualquer agente econômico possa ter qualquer tipo de evolução ao longo do período contábil.

\section{Custos de bem-estar da inflação com moeda remunerada}

Passemos agora ao quarto e último ponto a ser abordado neste texto. Trata-se da contribuição de Simonsen à questão dos custos de bem-estar da inflação quando ativos outros, que não a moeda não-remunerada, são utilizados com objetivos transacionais. Como salientamos anteriormente, esta contribuição não se encontra mencionada em qualquer das publicações anteriormente citadas.

A idéia da pesquisa sobre custos de bem-estar da inflação nasceu quando de meu primeiro período como visiting-scholar no Departamento de Economia da 
Universidade de Chicago, nos anos 1993 e 1994. Naquela época, Robert Lucas Jr. (então ainda não-laureado com o Prêmio Nobel), estava iniciando suas pesquisas nessa área (Lucas, 1993). Lucas elaborara duas seções de seu paper contemplando a existência de um sistema bancário que emitia ativos substitutos à moeda. Mas, do ponto de vista empírico (8), não estava satisfeito com nenhuma delas. Tanto que, na versão final desse trabalho, publicada na revista Econometrica em março de 2000, excluiu-as ambas.

Ao descrever a questão para Simonsen, este imediatamente interessou-se pelo tema. Isto posto, tive o privilégio de dividir com o Professor, como outras vezes fizera, a co-autoria dessa pesquisa. Desejo registrar que tais co-autorias revelavam sobretudo a grande generosidade de Mario Henrique Simonsen, tendo em vista que um trabalho assinado a quatro mãos pressupõe certa simetria intelectual entre co-autores, impossível de materializar-se nesse caso.

A pesquisa deu origem a Simonsen \& Cysne (1994; 1999; 2001). Trata-se de um trabalho construído inteiramente sobre os alicerces estabelecidos em Lucas (1993; 2000). Para entender seu posicionamento na evolução das idéias nesta área do conhecimento, cabe observar inicialmente que o trabalho de Lucas foi objeto de pelo menos dois tipos de críticas. A primeira diz respeito à superestimativa dos custos de bem-estar da inflação, para baixas taxas de juros, quando se utiliza, tal como em Lucas $(1993 ; 2000)$, a hipótese de uma elasticidade-juros constante da demanda por moeda. Isto se deve ao fato empírico, constatado por Mulligan \& Sala-i-Martin (1996), de que, para baixas taxas de juros, a demanda por moeda comporta-se de forma exatamente oposta àquela prevista pela Teoria Geral de Keynes: a elasticidade-juros reduz-se a algo próximo de zero. Isto posto, não haveria custos de bem-estar significativos para taxas de juros próximas de zero, ponto que não foi levado em consideração na estimação bi-logarítimica da demanda por moeda efetuada por Lucas, a qual implicava uma elasticidade constante. Seu trabalho estaria, dessa forma, superestimando os custos de bem-estar da inflação para baixas taxas de inflação.

A segunda crítica ao trabalho de Lucas, a que mais de perto aqui nos interessa, decorreu do fato de este autor utilizar, em suas mensurações do custo de bem-estar da inflação nos Estados Unidos, um agregado monetário (MI) somando ativos que pagam juros com ativos que não pagam juros, e de não fazer, seja teórica seja empiricamente, a devida distinção entre os mesmos. Esse ponto foi levantado, entre outros, por Marty (1999). Ponto semelhante foi criticado por E. Prescott em seus comentários sobre o trabalho de King \& Wolman (1996). Esse mesmo tipo de crítica poderia também ser colocado de outra forma, essa reconhecida por Lucas. Tratava-se de argumentar que agregados mais amplos, incluindo peremptoriamente ativos monetários que pagam juros, deveriam ser incluídos na análise teórica e empírica associada aos custos de bem-estar da inflação. 
Simonsen \& Cysne $(1994 ; 1999 ; 2001)$ dedicaram-se a responder exatamente este tipo de crítica - seja da forma colocada por Marty (1999), seja da forma autocolocada por Lucas. No trabalho deste, quanto maior a taxa de inflação de longo prazo, tanto maior a taxa nominal de juros, menor a utilização de moeda e maior o desvio de fatores produtivos para uso na provisão de serviços substitutos ao serviço da moeda. Isto define um custo de bem-estar sempre que a taxa nominal de juros se eleva acima de zero, pois fatores de produção que poderiam estar sendo utilizados na produção de bens de consumo são ineficientemente desviados para a produção de serviços monetários (os quais poderiam estar sendo supridos com custo social zero por meio da moeda).

Simonsen \& Cysne $(1994 ; 1999 ; 2001)$ repetem esse mesmo tipo de arrazoado, incluindo, todavia, também os custos inerentes à utilização de moeda remunerada. Um raciocínio semelhante foi efetuado tomando-se como base a queda na demanda pela moeda remunerada, o que ocorre sempre que o custo de oportunidade de mantê-la se eleva (esse custo de oportunidade é definido pela diferença entre a maior taxa de juros da economia e a taxa de juros paga pela moeda remunerada). Isto passa a definir um custo de bem-estar da inflação bidimensional, no qual tanto a demanda por moeda não-remunerada, quanto a demanda por moeda remunerada, são consideradas funções de seus respectivos custos de oportunidade.

Cysne (2000a) e Cysne (2000b) deram continuidade a esta pesquisa. Cysne (2000a) derivou condições de suficiência para que equações de demanda por ativos monetários sejam integráveis. Cysne (2000b) estendeu os resultados apresentados por Simonsen \& Cysne $(1994 ; 1999 ; 2001)$ em diferentes direções. O ponto mais importante residiu na eliminação da hipótese de Simonsen \& Cysne (razoavelmente forte) de que o diferencial entre o juro mais alto da economia e o juro da respectiva moeda remunerada se mantém constante.

\section{Conclusões}

As contribuições teóricas de Mario Henrique Simonsen são demasiado amplas para serem apresentadas em um, ou mesmo em um punhado de artigos. Ainda mais difícil seria listar suas contribuições em outras áreas (particularmente, na formação de recursos humanos e na formulação de políticas econômicas no Brasil). Assim, vários de seus ex-alunos e parceiros têm apresentado, marginalmente, como aqui procedemos, sua visão sobre a(s) mesma(s), fazendo com que, pouco a pouco, vários pontos importantes de sua rica trajetória profissional e pessoal venham à tona.

Neste artigo, limitei-me a apresentar quatro pontos que ainda não haviam sido mencionados na Coletânea Simonsen, de suas contribuições à teoria econô- 
mica. Dentre esses, concentrei-me mais na questão da contabilidade com juros reais e nos custos de bem-estar da inflação, assuntos com os quais tive maior contato. Aproveitei também para descrever para o leitor, na área de custos de bem-estar da inflação, como a contribuição de Simonsen tem dado origem a desenvolvimentos posteriores.

Espero que, em breve, os vários pontos aqui faltantes sejam devidamente complementados por contribuições congêneres. Particularmente da parte de estudiosos da área de História do Pensamento Econômico, dos quais certamente se poderá esperar maior rigor científico no que diz respeito ao efetivo pioneirismo nas várias contribuições de Mario Henrique Simonsen.

Notas

1 Como relatam com toda a propriedade José Luis Carvalho e Waldir Lobão (em Faro, 1998), "nunca conseguimos ver em Mario Henrique que não fosse professor", e "O Mario será sempre, para nós, o professor Simonsen”. Compartilhando tal imagem, neste texto, refiro-me algumas vezes a Mario Henrique Simonsen como "o Professor".

2 Trata-se da defesa da concorrência de uma área na qual a convergência em torno das opiniões de Simonsen foi menos abrangente do que na área de macroeconomia. Refiro-me, particularmente, às opiniões que pude observar ao conviver, durante algum tempo, por conta da administração do Centro de Estudos de Reforma de Estado e Defesa da Concorrência (CERES) da FGV, com os profissionais militantes na área. Percebi então dissensões com relação às opiniões de Simonsen, particularmente entre os profissionais do Direito. Em todos os casos que constatei, por motivos ortogonais à teoria econômica (Cysne, 1998 detalha esse ponto).

3 Devido ao pouco interesse de Simonsen pela publicação de seus trabalhos em revistas científicas internacionais, trata-se sempre de tarefa ingrata caracterizar com precisão $o$ pioneirismo de suas contribuições. Dentre os quatro pontos aqui levantados, apenas o último, relativo aos custos de bem-estar da inflação, não está sujeito a esse problema por ter dado origem a artigo publicado no Journal of Money Credit and Banking (Simonsen \& Cysne, 2001).

4 Marques (1985) apresenta detalhada exposição sobre os acontecimentos da época.

5 O leitor interessado no detalhamento técnico destas operações pode recorrer a Simonsen \& Cysne $(1985 ; 1987 ; 1989 ; 1995)$ ou Cysne (1990).

6 Tais referências incluem Simonsen \& Cysne (1985; 1987; 1989; 1995). A este respeito, veja-se a nota número 3 em Simonsen \& Cysne (1995: 159).

7 A versão então efetivamente utilizada do conceito de manutenção de capital de giro, correspondente ao lucro ilusório na reposição do ativo circulante, foi aquela (incompleta) estipulada pela Lei n. ${ }^{\circ} 4506$, de 1964 . A correção era incompleta porque permitia apenas a dedução da manutenção do capital de giro do imposto a pagar do imposto sobre lucros extraordinários, mas não do imposto de renda normal (Simonsen \& Campos, 1974: 133). 
8 Obtive esta informação de Robert Lucas Jr. em reposta à pergunta que lhe fiz (por que não incluíra tais seções em seu trabalho) assim que retornei a Chicago, em 2000.

Referências bibliográficas

ARAUJO, A. Comunicação verbal. EPGE-FGV, 2000.

BARBOSA, F.H. A contribuição acadêmica de Mario Henrique Simonsen. Revista de Econometria, v. 17, n. 1, 1997.

BLEJER, M. \& CHEASTY, A. The measurement of the fiscal deficits: analytical and methodological issues. Journal of Economic Literature, v. 29, n. 2, p. 1644-1678, 1991.

BOIANOVSKY, M. Simonsen and the early history of the cash-in-advance approach. Encontro Nacional de Economia da ANPEC, 27, Anais, Belém, 1999, p. 603-613.

CAMPOS, R.O. Mario Simonsen, um matemático humanista. Revista Brasileira de Economia, edição especial em homenagem ao professor Mario Henrique Simonsen, v. 52, 1998.

CATSAMBAS, T. Budget deficits, inflation accounting, and macroeconomic policy: a skeptical note, Journal of Public Policy, v. 8, n. 1, p. 49-60, 1988.

CHACEL, J.; SIMONSEN, M. H. \& WALD, A. A correção monetária. Rio de Janeiro, Apec Editora, 1970.

CYSNE, R.P. Contabilidade com juros reais, déficit público e imposto inflacionário. Pesquisa e Planejamento Econômico, v. 20, p. 161-190, abr. 1990.

Brasil 2001 e Brasil 2002 em 2001. FGV, Conjuntura Econômica, jan. 2001 [Trabalho apresentado no Encontro Nacional de Mercados Financeiros e Políticas Monetária e Cambial].

Integrability and monetary assets: an alternative approach to an old problem. Ensaio Econômico da EPGE, n. 397, 2000a.

Devise indexes, money and welfare. Ensaio Econômico da EPGE, n. $396,2000 b$.

Aspectos da defesa da concorrência no Brasil. Revista Brasileira de Economia, edição especial em homenagem a Mario Henrique Simonsen, v. 52, 1998.

EISNER, R. Which budget deficit? Some issues in measurement and their implications. The American Economic Review, v. 74, n. 2, p. 138-143, 1984.

EISNER, T \& PIEPER, P.J. A new view of the federal debt and budget deficits. The American Economic Review, v. 74, n. 1, p. 11-29, 1984.

FARO, C.D.L. (org.), Edição especial em homenagem ao professor Mario Henrique Simonsen. Revista Brasileira de Economia, v. 52, 1998.

GIL-DIAZ, F.G., F. Government budget measurement under inflation in LDCs, public finance and public debt. Congress of the International Institute of Public Finance, 40. Proceedings. Bernard P. Herber (ed.). Detroit, MI., 1986, p. 123-152. 
HAIG, R. (ed.). The concept of income: economic and legal aspects. In: The federal income tax. Columbia University Press, 1921.

HICKS, J.R. Value and capital, 2. ed. Oxford University Press, 1939.

KAHN, H. \& WIENER, A.J. Ano 2000: um arcabouço para especulação sobre os próximos trinta e cinco anos. Instituto Hudson, 1967.

KENNEDY, C. Inflation accounting: retrospect and prospect. Economic Policy Review, University of Cambridge, p. 58-64, 1978.

KING, R.G. \& WOLMAN, A. Inflation targeting in a St. Louis model of the 21 st century. The Federal Reserve Bank of St. Lowis Review, 1996.

LEAL, C.I.S. Edição especial em homenagem ao professor Mario Henrique Simonsen. Revista Brasileira de Economia, v. 52, 1998.

LEMOS, A.J. \& SCHYMURA, L.G. Aspectos da defesa da concorrência no Brasil: um estudo de caso. Revista Brasileira de Economia, edição especial em homenagem a Mario Henrique Simonsen, v. 52, 1998.

LUCAS JR., R.E. The welfare costs of inflation. Working Paper. University of Chicago, July, 1993.

LUCAS JR., R.E. Inflation and welfare. Econometrica, v. 68, n. 62, p. 247-274, Mar. 2000.

MARQUES, M.S.B. FMI: a experiência brasileira recente. IBRE-FGV, 1985 [mimeo.].

MARTY, A.L. The inflation tax and the marginal welfare cost in a world of currency and deposits, The Federal Reserve Bank of St. Louis Review, 76, p. 67-71, 1994.

The welfare cost of inflation: a critique of Bailey and Lucas. The Federal Reserve Bank of St. Lonis Review, 1999.

MARTY, A.L. \& CHALOUPKA, F. Optimal inflation rates: a generalization. Journal of Money, Credit and Banking, 20, p. 141-144, 1988.

MULLIGAN, C.B. \& SALA-I-MARTIN, X. Adoption of financial technologies: implications for money demand and monetary policy. NBER Working Paper 5504, National Bureau of Economic Research, 1996

OLIVEIRA, N.C., Mario Henrique Simonsen, EPGE-FGV, 2000 [mimeo].

PASTORE, A.C. Por que a política monetária perde eficácia. Revista Brasileira de Economia, v. 50, n. 3, 1996.

SIMONSEN, M.H. A Lei de Say e o efeito liquidez real. Revista Brasileira de Economia, v. 18, n. 1, p. 41-66, 1964.

Brasil 2001. Rio de Janeiro, Apec Editora, 1969.

Apec Editora, 1970.

Inflação: gradualismo versus tratamento de choque Rio de Janeiro, Brasil 2001. Rio de Janeiro, Apec Editora, 1972. 
SIMONSEN, M.H. Aspectos teóricos do Plano Collor. In: Plano Collor, avaliações e perspectivas. Revista Brasileira de Economia, edição especial, v. 45, jan. 1991.

Vargas, 1995.

30 anos de indexação. Rio de Janeiro, Editora da Fundação Getúlio

SIMONSEN, M.H. \& CAMPOS, R.O. A nova economia brasileira. Rio de Janeiro, José Olympio, 1974.

SIMONSEN, M.H. \& CYSNE, R.P. As contas nacionais. Ensaio Econômico da EPGE, n. 64,1985

As contas nacionais. Rio de Janeiro, Simposium Consultoria e Serviços Técnicos Ltda., 1987.

Macroeconomia. São Paulo, Atlas, 1989.

Macroeconomia, $2^{2}$ ed. Rio de Janeiro, Ao Livro Técnico Editora, 1995.

SIMONSEN, M.H. \& CYSNE, R.P. Welfare costs of inflation and interest-bearing deposits. Ensaio Econômico da EPGE/FGV, 1999, revised [original version, 1994].

Welfare costs of inflation and interest-bearing deposits. Journal of Money Credit and Banking, v. 33, n. 1., p. 99-100, Feb. 2001.

TAYLOR, C.T. \& THREADGOLD, A.R. Real national saving and its sectoral composition. Discussion Paper, n. 6, Bank of England, 1979.

WERLANG, S.R.C. Simonsen, inflação, expectativas racionais e os pós-keynesianos. Revista Brasileira de Economia, edição especial em homenagem ao professor Mario Henrique Simonsen, v. 52, 1998.

RESUMO - O AUTOR inicia o artigo efetuando uma breve revisão da literatura nacional que analisa as contribuições de Mario Henrique Simonsen à teoria econômica. Em seguida, detalham-se quatro pontos não abordados nos trabalhos revistos. Em particular, sua derradeira contribuição, referente à literatura sobre os custos de bem-estar da inflação, pesquisa que deu origem recentemente, cinco anos após o seu falecimento, a um artigo publicado no prestigioso Journal of Money, Credit and Banking.

ABSTRACT - THE AUTHOR starts the article by presenting a short a review of the Brazilian literature concerning the academic contributions of Mario Henrique Simonsen. In a subsequent step, four points not included in the works surveyed are detailed. Particularly, his last contribution, related to the welfare costs of inflation, which lead to an article published in February of 2001, five years after his death, in the prestigious Journal of Money Credit and Banking.

Rubens Penha Cysne, professor da Fundação Getúlio Vargas, é atualmente visiting scholar na Universidade de Chicago (biênio 2000-01)

O autor agradece, sem implicá-los nos erros porventura existentes, os comentários de Aloisio Araujo, Luis H.B. Braido, Humberto de A. Moreira, Paulo K. Monteiro e Sergio R.C. Werlang. 